\title{
THERMAL CONDUCTIVITY MEASUREMENTS OF NANOFLUIDS
}

\author{
M. I. Pryazhnikov ${ }^{1,2}$, A.V. Minakov ${ }^{1,2,3}$, V.Ya. Rudyak ${ }^{1,2}$, D.V. Guzei, ${ }^{2}$ \\ ${ }^{1}$ Siberian Federal University, Krasnoyarsk, Russia \\ ${ }^{2}$ Novosibirsk State University of Architecture and Civil Engineering, Novosibirsk, Russia \\ ${ }^{3}$ Kutateladze Institute of Thermophysics, SB RAS, Novosibirsk, Russia \\ Aminakov@sfu-kras.ru
}

The paper presents the results of systematic measurements of the thermal conductivity coefficient of nanofluids at room temperature. In total, more than fifty various nanofluids based on water, ethylene glycol, and engine oil containing particles of $\mathrm{SiO}_{2}, \mathrm{Al}_{2} \mathrm{O}_{3}, \mathrm{TiO}_{2}, \mathrm{ZrO}_{2}, \mathrm{CuO}$, and diamond were studied. The nanoparticles volume concentration ranged from 0.25 to $8 \%$ and the particles size ranged from 10 to $150 \mathrm{~nm}$. It is shown that the thermal conductivity of nanofluids is not described by the classical theories (Maxwell's and so forth). The nanofluid thermal conductivity coefficient is a complicated function not only of the particle concentration, but also the particles size, their material, and type of base fluid. Measured thermal conductivity coefficients almost always exceed the values calculated by the Maxwell's formula, though nanofluids with sufficiently small particles may have thermal conductivity coefficients even lower than those predicted by the Maxwell theory. However, in all cases, the nanofluid thermal conductivity coefficient enhances with increasing particle size. It is convincingly shown that there is no direct correlation between the thermal conductivity of the nanoparticle material and the thermal conductivity of nanofluid containing these particles. The base liquid also significantly influences the effective thermal conductivity of the nanofluid. It has been confirmed that the lower the thermal conductivity of the base fluid, the higher the relative thermal conductivity coefficient of the nanofluid.

Key words: thermal conductivity coefficient, nanofluid, nanoparticles, hot-wire method.

\section{Introduction}

Nanofluids represent a two-phase system consisting of base liquid and nanoparticles. The interest in nanofluids is associated with two main factors. Nanoparticles, because of their small size, have a number of unusual properties that are lacking in the dispersed macroscopic particles. The unusual properties of nanoparticles determine non-standard properties of nanofluids, which include these particles. Most expectations have long been associated with various thermal applications of nanofluids. As late as the first experiments on measurement of their thermal conductivity $[1,2]$ showed excellent results: the incorporation of even small, of the order of a percent fraction, concentrations of solid metal nanoparticles enhanced the thermal conductivity of the base fluid by 
several percent or even tens of percent. This initiated a number of thermal conductivity measurements of the nanofluids, though the obtained data proved to be surprisingly controversial. It was found that the thermal conductivity of nanofluids, as well as their viscosity not described by the classical theories (see the reviews [3-5]). In particular, it was found that the thermal conductivity of nanofluids depends not only on particle concentration but also on particle size. An unambiguous answer to the question of what is this relationship still fails.

Thus in [6], when studying water-based nanofluids with $\mathrm{Al}_{2} \mathrm{O}_{3}$ particles, it was argued that the thermal conductivity coefficient enhances with decreasing particle diameter. Similar data for the same nanofluids are given in [7,8]. The decrease in thermal conductivity with increasing nanoparticle size was also noted when studying other nanofluids [9-12]. In [13] it was asserted that the thermal conductivity coefficient increases linearly with decreasing particle size (the measurements were carried out in water-based nanofluid with nanoparticles of $\mathrm{TiO}_{2}$ and $\mathrm{ZnO}$ ).

On the other hand, Chen et al. [14], based on measurements of thermal conductivity of waterbased nanofluids with $\mathrm{SiO}_{2}$ particles came to just the opposite conclusion: thermal conductivity enhances with the increasing of particle size. Similar data for nanofluids with particles of $\mathrm{Al}_{2} \mathrm{O}_{3}, \mathrm{SiC}$ and Au were reported in [15-19].

The dependence of the thermal conductivity of nanofluids on material particles is discussed in [20]. It is alleged that there is no direct connection between the thermal conductivity of material nanoparticle and the thermal conductivity of the nanofluids.

The available data on the degree of thermal conductivity enhancement in nanofluids are quite controversial. Along with the previously mentioned works, which noted a much higher enhancement of the thermal conductivity coefficient than predicted by classical theory, there are also assertions that these measurements can be adequately described by Maxwell's theory [21] (see the papers [2-5, 22]). These conflicting data do not allow formulating neither possible mechanisms nor nanofluid thermal conductivity models, though about a dozen of such models are available in literature (see for example [23-26] and the literature quoted there).

Even a brief review shows that the systematic measurement of the nanofluid thermal conductivity and definition of influencing parameters is a crucial problem. The present work is concerned exactly with this topic. In total, more than fifty various nanofluids based on distilled water, ethylene glycol, and engine oil containing particles of $\mathrm{SiO}_{2}, \mathrm{Al}_{2} \mathrm{O}_{3}, \mathrm{TiO}_{2}, \mathrm{ZrO}_{2}, \mathrm{CuO}$, and diamond were studied. The nanoparticles volume concentration ranged from 0.25 to $8 \%$. The particle size ranged from 5 to $150 \mathrm{~nm}$.

\section{Measurement technique}


Thermal conductivity measurements were performed by non-stationary hot-wire method. Detailed description of the test bench and testing technique is given in [27]. Wheatstone bridge was used as the basis of the test bench instrumentation to measure an unknown electrical resistance of hot wire. A copper wire with a length of $150 \mathrm{~mm}$ and a diameter of 75 microns was used in the experiments. The basic electric circuit of the setup is presented in Fig. 1. The wire serves one of the measuring bridge resistors $R_{w}$. The bridge includes also two other resistors: $R_{1}=2 \mathrm{kOhm}$ and $\mathrm{R}_{3}=1$ Ohm as well as the resistance box $R_{2}$, needed to balance the bridge. Initially the bridge is balanced and the output voltage does not exceed $10 \mu \mathrm{V}$. Balancing of the measuring circuit is carried out by a voltage of $0.1 \mathrm{~V}$ from a lab power source GWInstek GPC-3060D applied within a short period of time. Further, the circuit is energized by measuring voltage to record the out-of-balance voltage change of the bridge circuit over time. Voltage measurement is carried out using a precision voltmeter GWInstek GDM-78261 with increments of $10 \mathrm{~ms}$. In addition, the test fluid temperature was measured by means of chromel-copel thermocouples connected to the TRM-138 meter.

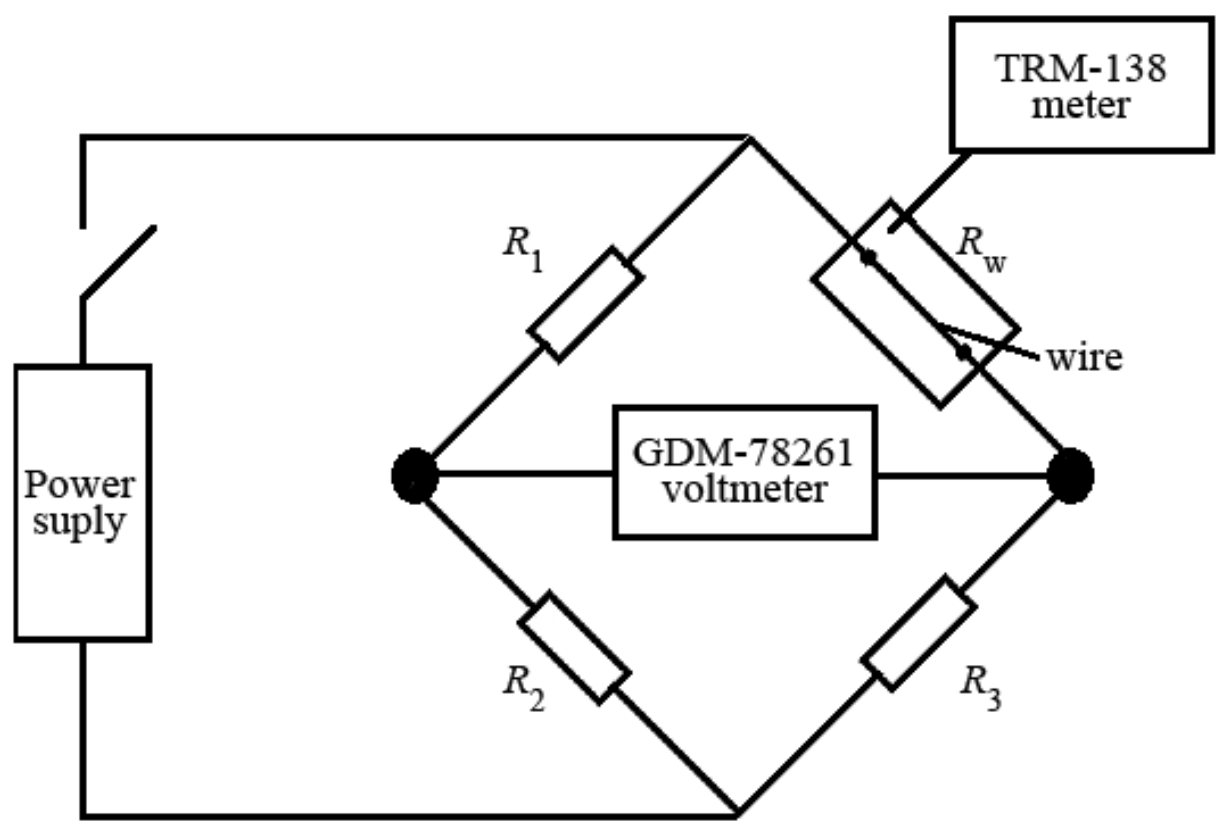

Fig. 1. The electric circuit of the experimental setup.

Data processing was made in a following way. The initial resistance of the wire is found from the condition of the bridge circuit balance: $R_{w 0}=R_{1} R_{3} / R_{2}$. The change in wire resistance is determined by the ratio

$$
R_{w t}=\frac{R_{3}\left[R_{1}+\frac{V_{o}\left(R_{1}+R_{2}\right)}{V_{i}}\right]}{R_{2}-\frac{V_{o}\left(R_{1}+R_{2}\right)}{V_{i}}},
$$


where $V_{i}$ is the input voltage of the bridge, $V_{o}$ is out-of-balance bridge voltage. Given the dependence of electrical resistance of copper on temperature, we can determine the temperature change of the wire

$$
\Delta T=\left(R_{w t 2}-R_{w t 1}\right) /\left(\alpha R_{w 0}\right)=\Delta R_{w t} /\left(\alpha R_{w 0}\right)
$$

where $\alpha=0.0003831 / \mathrm{K}$ is the temperature coefficient, predetermined from measurement series of used copper wire resistance at different temperatures. The voltage drop on the wire is given by formula: $V_{R w}=V_{i} R_{w t} /\left(R_{w t}+R_{3}\right)$. Then, the linear density of heat flux on the wire is defined as $q=\left(V_{R w}\right)^{2} / L_{w} R_{w t}$ where $L_{w}$ is the length of the wire. In the experiments, a typical value of $q$ was around $10 \mathrm{~W} / \mathrm{m}$.

Eventually, the heat conductivity coefficient of a fluid is defined as follows: $\lambda=\left(\alpha q R_{w 0}\right) /(4 \pi G)$, where $G$ is the angular coefficient of the linear section taken from the dependence of the wire resistance on the logarithm of time. The coefficient $G$ was calculated by the least squares method. The value of thermal conductivity coefficient was obtained by averaging over ten measurements. During the measurements, the nanofluid temperature was maintained constant. In the presented measurements it was equal to $25^{\circ} \mathrm{C}$. The resultant relative measurement error of fluid thermal conductivity coefficient does not exceed $3 \%$.

Preparation of nanofluids was carried out based on standard two step process. After adding to the base fluid the required amount of nanopowder, the nanofluid was first thoroughly mixed mechanically, and then was placed for the half-hour into an ultrasonic disperser Sapphire to destruct conglomerates of particles. The nanoparticles were purchased from "Plasmoterm" company (Moscow).

\section{Dependence of thermal conductivity on particle concentration}

The first question that arises in the study of thermal conductivity of any dispersed fluid is formulated quite simply: how thermal conductivity depends on the particle concentration $\varphi$. The answer to this question for coarse dispersed liquids with spherical particles was given by Maxwell [21], who obtained the following relation between the thermal conductivity coefficient of the suspension $\lambda$ and base fluid $\lambda_{f}$

$$
\lambda=\lambda_{f}\left[1+\frac{3(1-\varpi) \varphi}{1+2 \varpi-\varphi(1-\varpi)}\right]
$$

where $\varpi=\lambda_{f} / \lambda_{p}, \lambda_{p}$ is the thermal conductivity coefficient of particle material. Formula (1) was obtained for spherical particles non interacting with each other. Later Bruggemann [28] proposed a model, which took into account the interaction of the randomly distributed particles. This model, unlike (1), has no restrictions on particle concentration, though within the low concentration range it leads to the same results as the Maxwell model. Hamilton and Crosser [29] generalized the model (1) 
for the case of non-spherical particles. There are still quite a lot of models, a short list of which can be found, for example in [22], however, the model (1) satisfactorily describes numerous experimental data obtained in coarse dispersed fluids at not too high concentrations.

Measured data on the relative thermal conductivity coefficient $\lambda_{r}=\lambda / \lambda_{f}$ for a number of water based nanofluids are presented in Table 1. In all cases, increasing the particle concentration leads to significant enhancement of nanofluid thermal conductivity. The enhancement of nanofluid thermal conductivity over that of pure water at $6 \%$ concentration of nanoparticles reaches $5-28 \%$ that is greater than the values defined by formula (1). For illustration, Fig. 2 shows nanofluids thermal conductivity coefficients, presented in the Table, along with the values calculated by formula (1).

Table 1. Relative thermal conductivity coefficient of water based nanofluids depending on the particle concentration.

\begin{tabular}{|c|c|c|c|c|c|c|c|}
\hline \multicolumn{2}{|c|}{$\mathrm{Al}_{2} \mathrm{O}_{3}(150 \mathrm{~nm})$} & \multicolumn{2}{|c|}{$\mathrm{TiO}_{2}(150 \mathrm{~nm})$} & \multicolumn{2}{l|}{$\mathrm{ZrO}_{2}(44 \mathrm{~nm})$} & \multicolumn{2}{l|}{$\mathrm{ZrO}_{2}(105 \mathrm{~nm})$} \\
\hline$\varphi$ & $\lambda / \lambda_{f}$ & $\varphi$ & $\lambda / \lambda_{f}$ & $\varphi$ & $\lambda / \lambda_{f}$ & $\varphi$ & $\lambda / \lambda_{f}$ \\
\hline 0.01 & 1.059 & 0.01 & 1.048 & 0.02 & 1.077 & 0.02 & 1.087 \\
\hline 0.02 & 1.131 & 0.02 & 1.100 & 0.04 & 1.143 & 0.04 & 1.169 \\
\hline 0.04 & 1.178 & 0.04 & 1.146 & 0.06 & 1.172 & 0.06 & 1.216 \\
\hline 0.06 & 1.240 & 0.06 & 1.206 & 0.08 & 1.185 & 0.08 & 1.283 \\
\hline
\end{tabular}
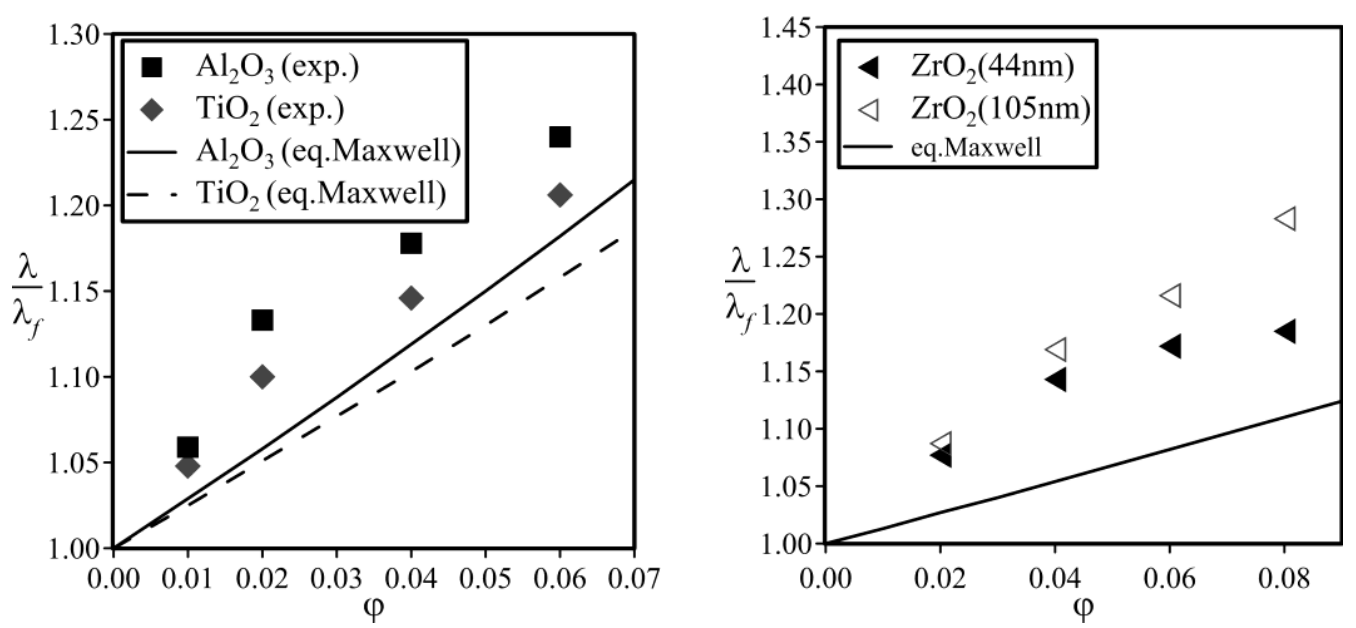

Fig. 2. Relative thermal conductivity of water based nanofluids with $150 \mathrm{~nm}$ particles of $\mathrm{TiO}_{2}, \mathrm{Al}_{2} \mathrm{O}_{3}$ (left), and $\mathrm{ZrO}_{2}$ (right) depending on particle concentration.

A characteristic feature of the nanofluid thermal conductivity is slowdown of its enhancement with increasing of particle concentration. This is well illustrated by Fig. 2 (right) for nanofluid with 44 $\mathrm{nm}$ particles of $\mathrm{ZrO}_{2}$. Similar behavior of the nanofluid thermal conductivity was noted earlier in 
experiments [30, 31], as well as in molecular dynamic simulations [32, 33]. At low concentrations of particles this dependence can be approximated by a simple formula

$$
\lambda_{r}=1+b_{1} \varphi-b_{2} \varphi^{2}
$$

However, the coefficients in formula (2) are not universal. Thus, for the nanofluid containing $150 \mathrm{~nm}$ particles of $\mathrm{Al}_{2} \mathrm{O}_{3}$

$$
\lambda_{r}=1+6.42 \varphi-39.5 \varphi^{2}
$$

for $150 \mathrm{~nm}$ particles of $\mathrm{TiO}_{2}$

$$
\lambda_{r}=1+4.82 \varphi-23.1 \varphi^{2}
$$

for $44 \mathrm{~nm}$ particles of $\mathrm{ZrO}_{2}$

$$
\lambda_{r}=1+4.68 \varphi-29.6 \varphi^{2}
$$

while for $105 \mathrm{~nm}$ particles of $\mathrm{ZrO}_{2}$

$$
\lambda_{r}=1+4.55 \varphi-12.7 \varphi^{2}
$$

\section{Dependence of thermal conductivity on particle size}

Analysis of the data in Table 1 and Fig. 2 (right) shows that the non-universality of the coefficients $b_{i}$ in formulas (2) and (3). In particular, from the fact that they are functions of the nanoparticle size $d_{p}$. In order to clearly answer the question about the character of this dependence, it was necessary to perform thermal conductivity measurements in nanofluids with particles of different size, though at the same volumetric concentration. We have performed these measurements using nanofluids with silicon, aluminum, zirconium, and titanium oxides particles. The particle sizes ranged from 10 to $150 \mathrm{~nm}$. Distilled water was used as the base fluid in all cases, while volume concentration of the nanoparticles was equal to $2 \%$. The measurements were carried out at a temperature of $25^{\circ} \mathrm{C}$. The data obtained are presented in Table 2 and allow us to unambiguously assert that the nanofluid thermal conductivity coefficient depends on the particle size; at that, the more particle size the higher thermal conductivity.

Table 2. Relative thermal conductivity coefficient of water based nanofluids depending on particle size.

\begin{tabular}{|c|c|c|c|c|c|c|c|}
\hline \multicolumn{2}{|c|}{$\mathrm{SiO}_{2}$} & \multicolumn{2}{|c|}{$\mathrm{Al}_{2} \mathrm{O}_{3}$} & \multicolumn{2}{c|}{$\mathrm{TiO}_{2}$} & \multicolumn{2}{c|}{$\mathrm{ZrO}_{2}$} \\
\hline$d_{p}$ & $\lambda / \lambda_{f}$ & $d_{p}$ & $\lambda / \lambda_{f}$ & $d_{p}$ & $\lambda / \lambda_{f}$ & $d_{p}$ & $\lambda / \lambda_{f}$ \\
\hline 10 & 1.015 & 50 & 1.061 & 71 & 1.066 & 44 & 1.077 \\
\hline
\end{tabular}




\begin{tabular}{|c|c|c|c|c|c|c|c|}
\hline 16 & 1.027 & 75 & 1.082 & 100 & 1.084 & 105 & 1.087 \\
\hline 25 & 1.040 & 100 & 1.100 & 150 & 1.100 & - & - \\
\hline 100 & 1.072 & 150 & 1.133 & - & - & - & - \\
\hline
\end{tabular}

However, the degree of enhancement of thermal conductivity coefficient is very different. It is characteristic that for different nanofluids we obtained relative thermal conductivity coefficients lower (see Fig. 3-4) than those defined by formula (1), which is shown as a dashed line. This fact was noted in the literature before, though was not associated with the relationship between the thermal conductivity and particle size [20]. Data for the water based nanofluids with $\mathrm{SiO}_{2}, \mathrm{TiO}_{2}$ and $\mathrm{Al}_{2} \mathrm{O}_{3}$ particles are compared in Fig. 3, 4 with experimental data [15, 34-40], while the dashed line corresponds to formula (1). Our data are generally in good agreement with data of other authors.

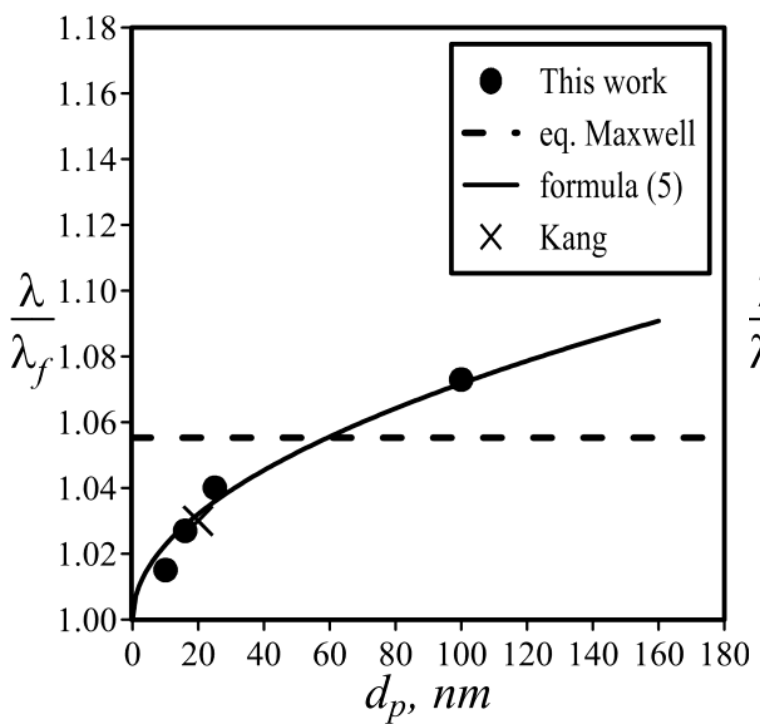

a)

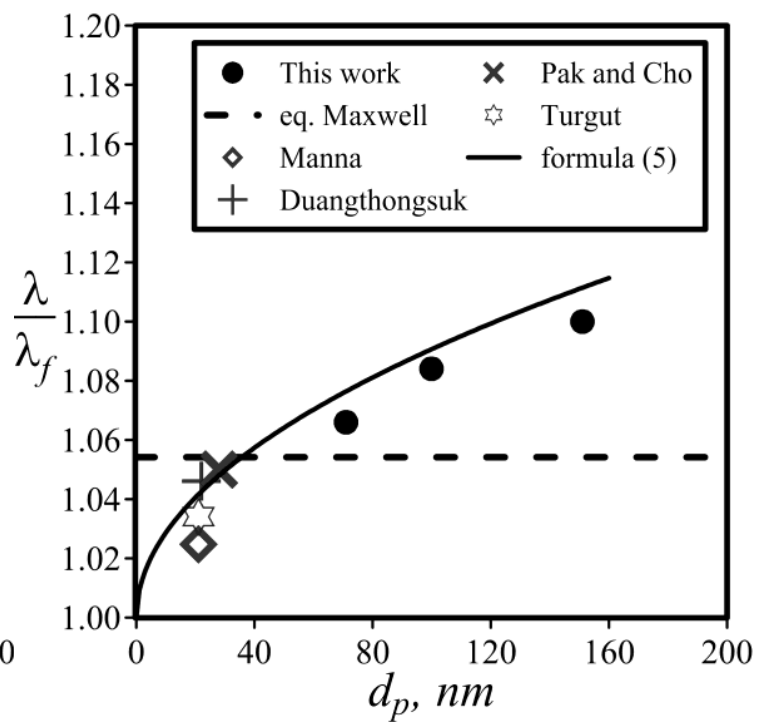

b)

Fig. 3. Relative thermal conductivity coefficients of $\mathrm{SiO}_{2}$ (a) and $\mathrm{TiO}_{2}$ (b) nanofluids versus nanoparticle diameter at volumetric concentration of $2 \%$.

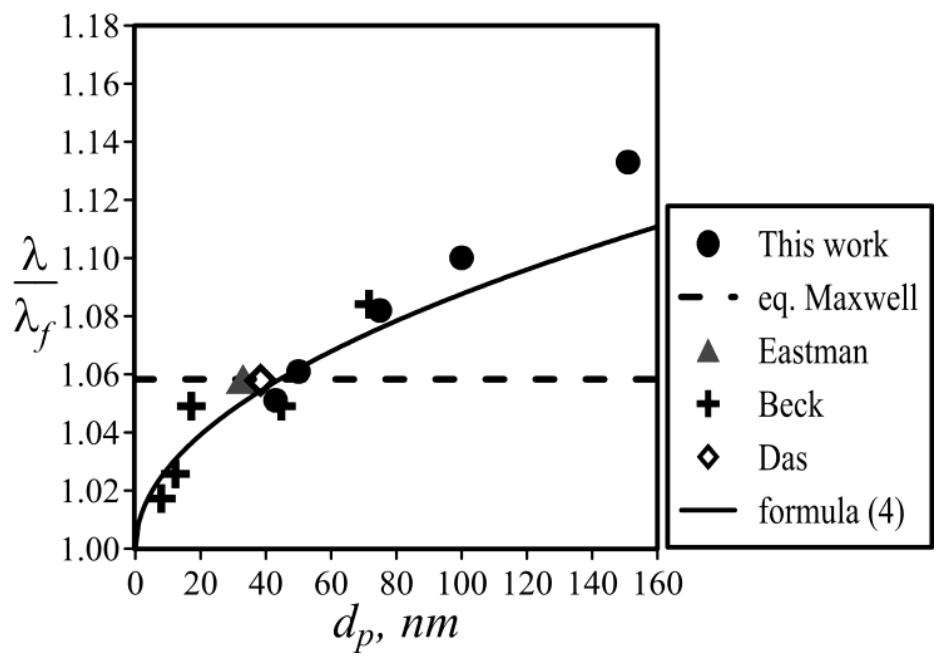

Fig. 4. Relative thermal conductivity coefficients of water based nanofluid with $\mathrm{Al}_{2} \mathrm{O}_{3}$ particles versus nanoparticle diameter at volumetric concentration of $2 \%$. 
What the dependence of thermal conductivity on particle size looks like? In [41], based on the analysis of numerous experimental data, it was shown that the relative thermal conductivity coefficient of water based nanofluid with particles of $\mathrm{Al}_{2} \mathrm{O}_{3}$ can be satisfactorily approximated by the formula

$$
k_{r}=1+A \sqrt{\varphi \tilde{D}}
$$

where $\tilde{D}=d_{p} / \sigma, \sigma$ is the effective size of the base fluid molecule, $A=0.038$ for nanofluids with $\mathrm{Al}_{2} \mathrm{O}_{3}$ particles. The comparison of the experimental data with the formula (4) is shown in Fig. 4 by the solid line. Formula (4) give the accuracy about $3 \%$.

The constant $A$ depends on nanoparticle material. It is clear, however, that this dependence is applicable only to certain sizes of particles. To the extent of large particle sizes such dependence must disappear, while the thermal conductivity coefficient should be described by the formula (1), since it well describes the existing experimental data for coarse fluids. Thus, the enhancement of thermal conductivity coefficient caused by the increase in particle size cannot be unlimited, and accordingly the dependence of the thermal conductivity coefficient on particle size should have maximum.

\section{Dependence of thermal conductivity on nanoparticle material}

All of the classical thermal conductivity theories of disperse fluids suggest dependence of thermal conductivity on particle material. In equation (1), this dependence is taken into account by introduction of thermal conductivity coefficient of the particle material. Figure 5 presents consolidated data from Table 2, obtained by the authors. Since these data include nanofluids with particles of the same size but different materials, it is clear that the nanofluid thermal conductivity depends on the particle material. Let us consider, what determines this dependence.

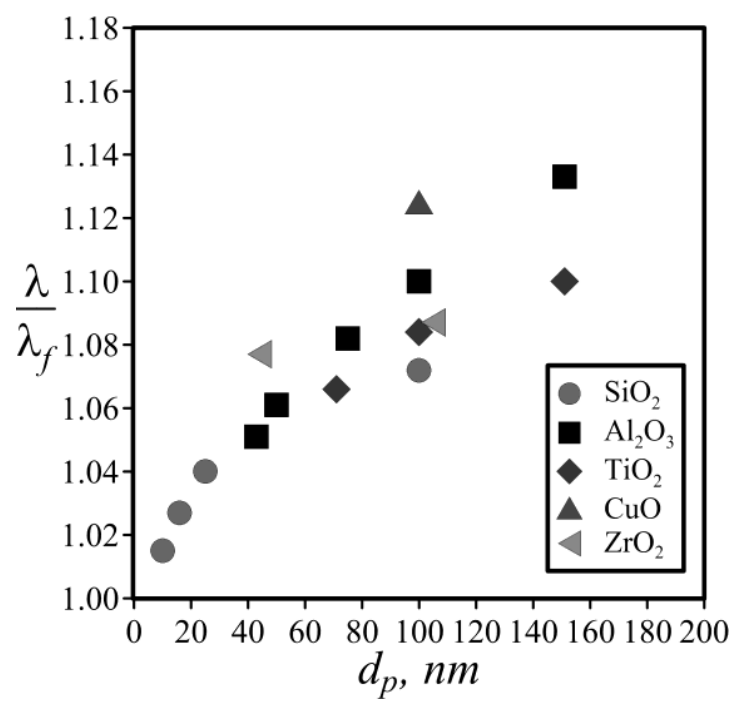

Fig. 5. Relative thermal conductivity coefficient of water based nanofluids depending on particle size at room temperature and volumetric concentration of $2 \%$. 
The first thing we need to understand is whether there is any systematic dependence of the nanofluid thermal conductivity coefficient on the nanoparticle thermal conductivity. The answer to this question is given by data presented in Fig. 6, which shows the dependence of the relative thermal conductivity of the five water based nanofluids with particles of $\mathrm{ZrO}_{2}, \mathrm{TiO}_{2}, \mathrm{SiO}_{2}, \mathrm{CuO}$, and $\mathrm{Al}_{2} \mathrm{O}_{3}$. In all cases, the average particle size was $100 \mathrm{~nm}$. Nanoparticles volume concentration is equal to $2 \%$. Here dashed line shows calculation by Maxwell formula (1). Thermal conductivity coefficients of particle material are ranged in a following ascending order: $\mathrm{ZrO}_{2}, \mathrm{TiO}_{2}, \mathrm{SiO}_{2}, \mathrm{CuO}$, and $\mathrm{Al}_{2} \mathrm{O}_{3}$. On the other hand, the data in Fig. 5 on nanofluid thermal conductivity coefficients are also ranged in ascending order as follows: $\mathrm{SiO}_{2}, \mathrm{TiO}_{2}, \mathrm{ZrO}_{2}, \mathrm{Al}_{2} \mathrm{O}_{3}$, and $\mathrm{CuO}$. It is obvious that there is no direct correlation between nanofluid thermal conductivity and that of particle material.

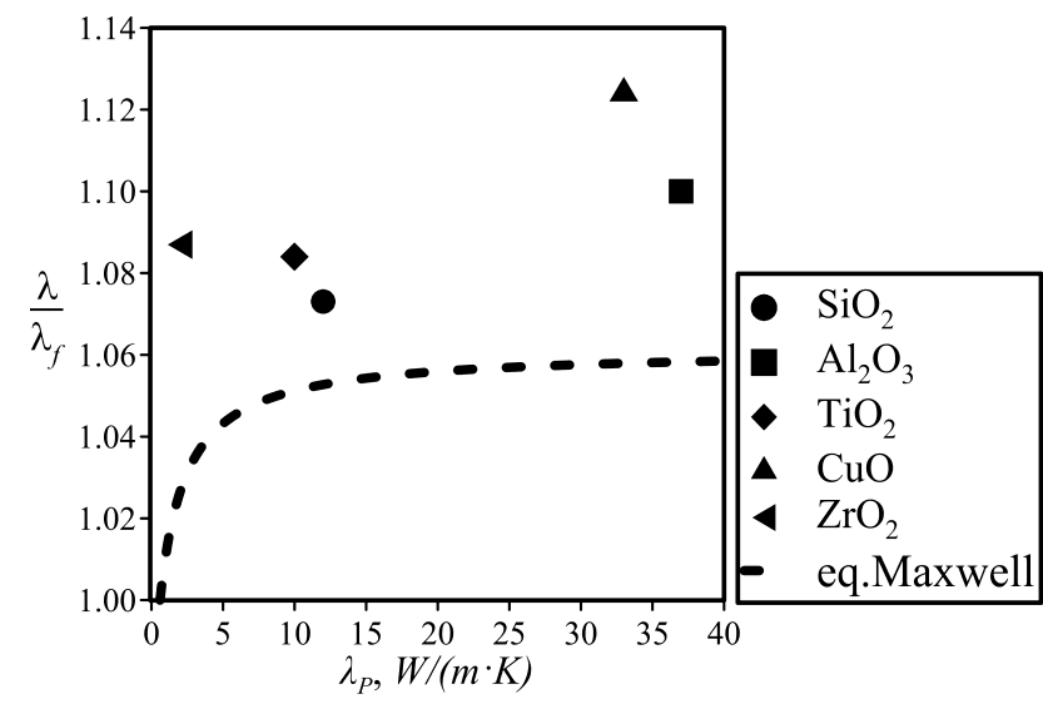

Fig. 6. Relative thermal conductivity coefficient of water based nanofluid depending on thermal conductivity of the particle material.

The nanofluid thermal conductivity coefficient is not correlated with the other important thermal characteristics of the nanoparticle material. This is illustrated by Fig. 7a and 7b, which present, respectively, the dependence of the relative thermal conductivity coefficients of nanofluids on thermal diffusivity and heat capacity of the particle material. All data are given for the same nanofluids as data in Fig. 5. 


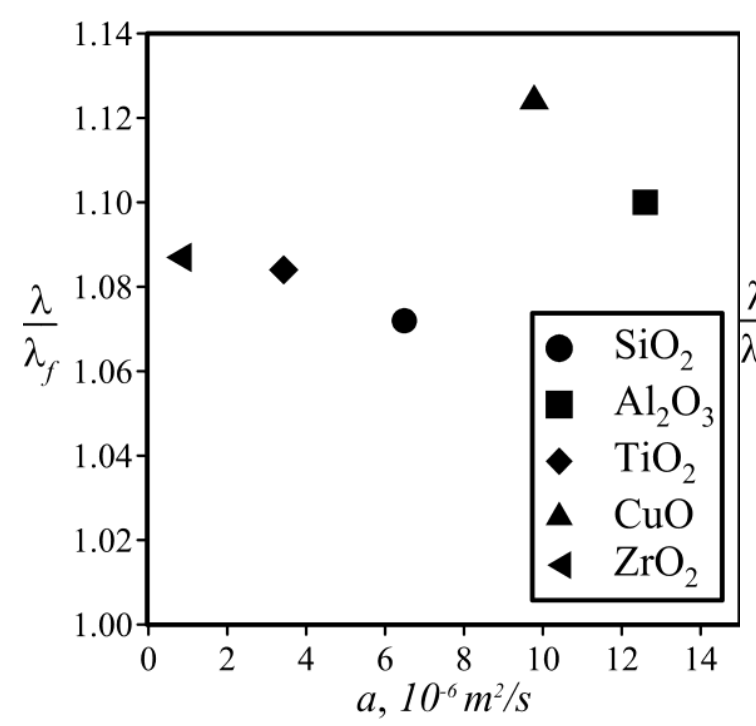

a)

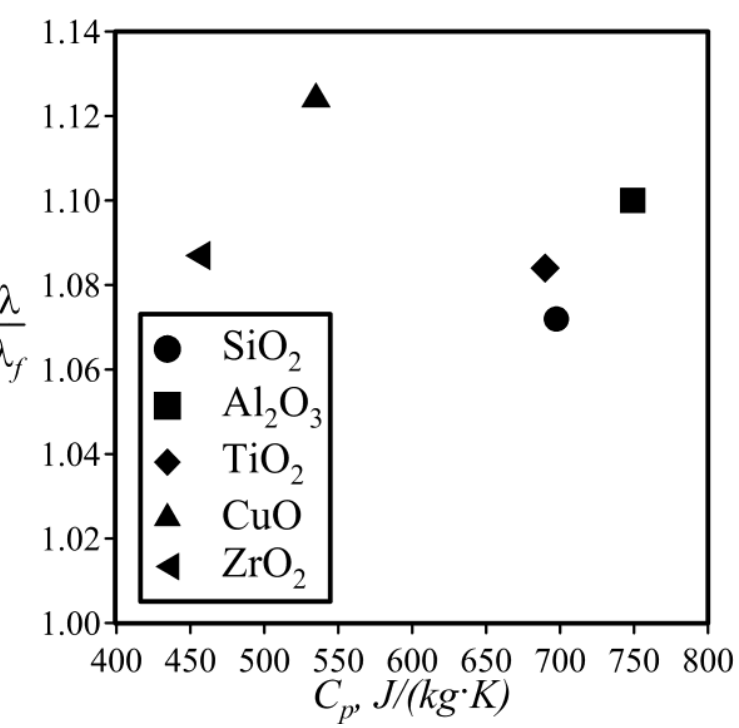

b)

Fig.7. Relative thermal conductivity coefficient of nanofluids versus thermal diffusivity (a) and heat capacity (b) of the particle material.

On the other hand, it was revealed by the molecular dynamics method $[32,33]$ that nanofluid thermal conductivity enhances with the increase in the nanoparticle material density. Our experimental data confirm this. Figure 8 shows the dependence of thermal conductivity on density particle material. This dependence was obtained for particle concentration of $2 \%$ and a particle size about $100 \mathrm{~nm}$. For comparison also shows data from other papers [42-45] for a close conditions. Indeed, the thermal conductivity of nanofluids is increased if the density of the nanoparticle material grows.

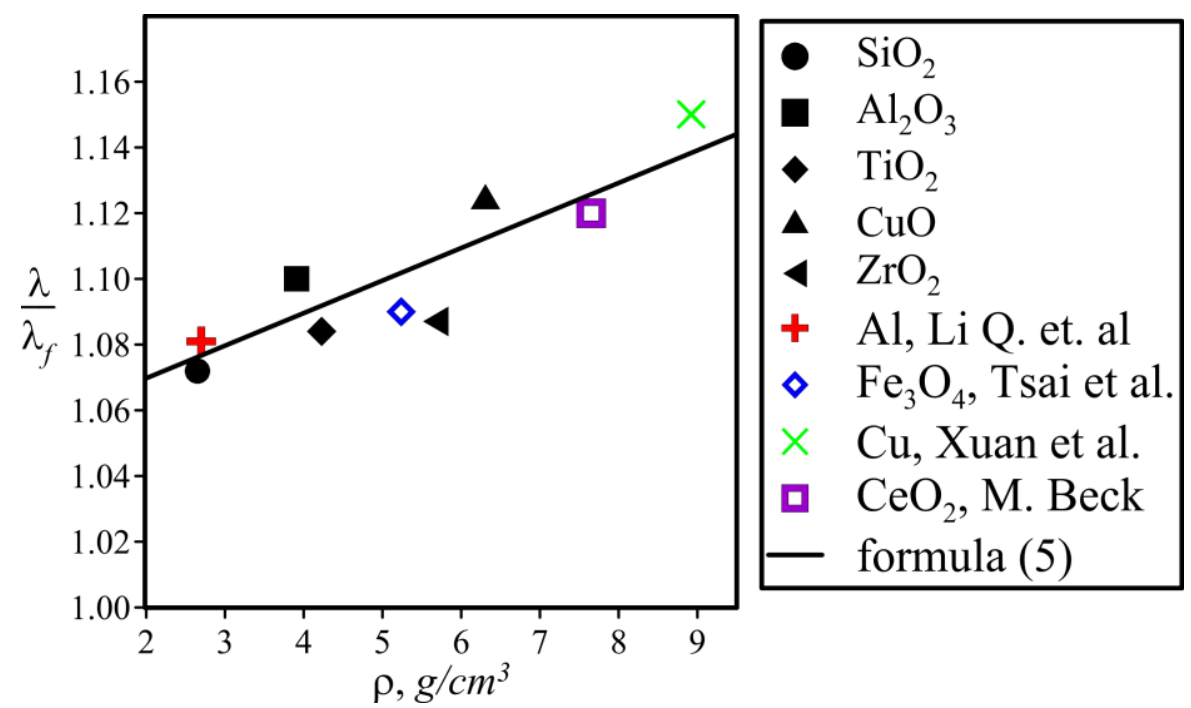

Fig. 8. Relative thermal conductivity of water based nanofluids versus density of particle material for volumetric concentration of $2 \%$ and particle size of $100 \mathrm{~nm}$. 
The authors of the paper [41] noticed that the constant $A$ in formula (4) should be function of the density of nanoparticles material but they could determine this constant only for nanofluids with $\mathrm{Al}_{2} \mathrm{O}_{3}$ particles. Analyzing the dependence in Fig. 8, we can conclude that this dependence is satisfactory described by linear function. Therefore we modified the formula (4) by the following one

$$
k_{r}=1+(0.0193+0.00383 \tilde{\rho}) \sqrt{\varphi \widetilde{D}} .
$$

Here $\tilde{\rho}=\rho_{p} / \rho_{f}, \rho_{p}, \rho_{f}$ are the density of the nanoparticle and carrier liquid material respectively. Figures 3 show (solid lines) a comparison of results obtained by this formula with the data of our and other experiments for different nanoparticles. In all cases, the agreement is good. The error of the formula (5) is less than $3 \%$.

\section{Dependence of thermal conductivity on the properties of the base fluid}

To date, just a few works are known, where the effect of base fluid properties on nanofluid thermal conductivity was studied. This was first done in [2], which deals with nanofluids based on water, ethylene glycol, vacuum pump oil, and engine oil. It was noted that the highest thermal conductivity of the nanofluid was revealed in ethylene glycol based nanofluids. Later, the influence of the base fluid was studied by Xie et al. [46]. They developed a method to create a stable nanofluids, based on deionized water, ethylene glycol, and decene with multiwalled carbon nanotubes. It was found that the thermal conductivity coefficient enhancement decreases with increasing thermal conductivity of the base fluid. This conclusion is not consistent with the data presented in paper [2], though, certainly, the studied nanofluids were quite specific. Therefore, it was extremely important to test the applicability of this conclusion with regard to the conventional nanofluids.

The complexity of studying the effects of the thermal conductivity of the base fluid on the thermal properties of nanofluids consists in the necessity to compare the data, at least of two nanofluids with the same concentration of nanoparticles and their size, though different base fluids. In the present work, the first measurement series was carried out with nanofluids based on water and ethylene glycol, containing $\mathrm{TiO}_{2}$ particles $150 \mathrm{~nm}$ in size. The data obtained differ systematically, though not much (see Fig. 9, left). In all cases, thermal conductivity enhancement of ethylene glycol based nanofluids is higher than that of water based nanofluids. At that, thermal conductivity coefficient of water is almost two and a half times higher than that of ethylene glycol. 

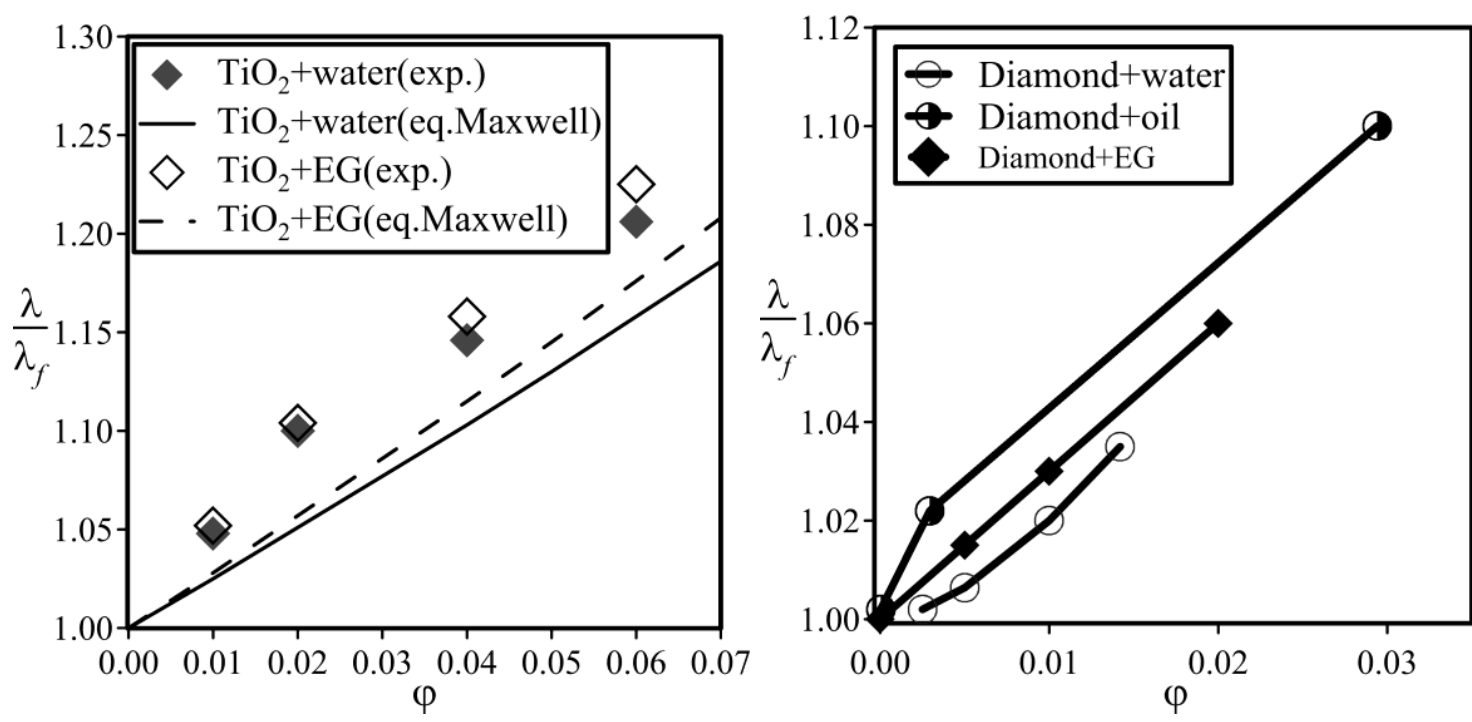

Fig. 9. Relative thermal conductivity coefficient of water and ethylene glycol based nanofluids depending on $\mathrm{TiO}_{2}$ particle concentration (left); and similar dependence of the nanofluids based on water, ethylene glycol and engine oil depending on diamond particle concentration (right).

In the second series of measurements we used the nanofluids based on water, ethylene glycol and engine oil with diamond particles with an average size of $5 \mathrm{~nm}$. Here the differences are more significant (see Fig. 9, right). The relative thermal conductivity coefficient of nanofluid, based on machine oil, is significantly higher than that for nanofluid, based of ethylene glycol and water. At that, the thermal conductivity coefficient of engine oil is almost twice lower than that of ethylene glycol and almost five times lower than that of water.

The stability of nanofluid can be improved by addition of various surfactants. Thermophysical properties of nanofluids containing surfactants differ in general from the properties of nanofluids with no surfactants. In order to determine the effect of surfactant on the thermal conductivity coefficient of water based nanofluid with $100 \mathrm{~nm}$ particles of $\mathrm{Al}_{2} \mathrm{O}_{3}$, we have carried out corresponding measurements. The volumetric concentration of the nanoparticles was $2 \%$. An acrylic polymer with a molecular mass of $20 \mathrm{MDa}$, and anionic charge of $40 \%$ was used as a surfactant. The concentration of polymer ranged from 50 to $200 \mathrm{mg} / \mathrm{l}$, i.e. mass concentration of the surfactant varied from 0.008 to $0.02 \%$. The thermal conductivity coefficient of water with additives of such surfactants practically did not differ from the corresponding values for water. The conducted measurements have shown that within the whole investigated range of surfactant concentrations, the nanofluid thermal conductivity coefficient did not change within the accuracy of measurements.

\section{Conclusion}

Let formulate the main conclusions obtained in this paper. First of all, it should be noted that the nanofluid thermal conductivity is not described by the classical theories, including the Maxwell 
theory (1) for coarse dispersed fluids. The main difference is that the nanofluid thermal conductivity coefficient is a complicated function not only of the particle concentration, but also the particle size, material, and type of base fluid.

The dependence of the thermal conductivity coefficient on the nanoparticle concentration, which typically is relatively small, is described by a correlation of the form (2). The coefficients $b_{i}$ involved in (2), are not universal, they depend on the nanoparticle size and material. The dependence of the nanofluid thermal conductivity coefficient on the nanoparticle size, as a rule, is well described by the power function (see also formulas (4) and (5)). Measured thermal conductivity coefficients almost always exceed the values calculated by formula (1), though nanofluids with sufficiently small particles may have thermal conductivity coefficients even lower than those predicted by the Maxwell theory. However, in all cases, the nanofluid thermal conductivity coefficient enhances with increasing particle size. Starting with a certain particle size, the measured nanofluid thermal conductivity coefficients exceed the values predicted by classical theories (in particular, by formula (1)). Within the studied range of concentrations this exceedance changes from a few percent to $10-15 \%$. At that, the relative enhancement of the thermal conductivity coefficient may reach 25-30\% (see Table 1). In general, thermal conductivity coefficient of the studied nanofluids containing metal oxides and silicon are significantly lower than those of nanofluids with metal particles (e.g., see the review [47]).

By definition, nanoparticles are particles sized from 1 to $100 \mathrm{~nm}$. In the present work we studied the thermal conductivity of both nanofluids and dispersed fluids with larger particles. At that, in all cases we observed a monotonic enhancement of thermal conductivity with increasing particle size. However, as already mentioned, noted enhancement of thermal conductivity coefficient with increase in particle size cannot be unlimited. Determining the nature of dependence of the thermal conductivity coefficient in dispersed fluids on size of the particles larger than $100 \mathrm{~nm}$ requires further systematic study.

Effect of the nanoparticle material is an extremely important factor in terms of creating nanofluids with control properties. Today it is convincingly shown that there is no direct correlation between the thermal conductivity of the nanoparticle material and the thermal conductivity of nanofluid containing these particles. This is quite important fact, since up to date there are attempts to postulate the existence of such a relationship, in particular, when building different thermal conductivity models. At the same time, the experiments prove the fact that nanofluid thermal conductivity depends on particle material. The measurements, performed in this work, indicate that the greater the density of nanoparticle material the higher nanofluid thermal conductivity. This is consistent with the data of molecular-dynamic modeling [32, 33]. This point of view allows us to explain much higher thermal conductivity values of nanofluids with metal particles (see, for example 
the paper [48] and references cited here). The density of all the metal nanoparticles ( $\mathrm{Fe}, \mathrm{Cu}, \mathrm{Ag}, \mathrm{Au}$, etc.) is typically much higher than density oxides used in our work.

In our experiments it was shown that small concentration of the surfactant does not change the thermal conductivity of the nanofluids. However we studied the nanofluids with large nanoparticles. The film thickness of the surfactant is of the order of 1-2 nanometers. Such film does not change practically neither the size of particles, nor their density. At the same time similar film may essentially change the size and especially density of small nanoparticles. In this case the thermal conductivity of nanofluids may be changed considerably.

The base liquid also significantly influences the effective thermal conductivity of the nanofluid. In this work we have confirmed that the lower the thermal conductivity of the base fluid, the higher the relative thermal conductivity coefficient of the nanofluid. This is quite naturally explained by the fact that in the base fluid with the highest thermal conductivity the enhancement of thermal conductivity is weaker, at other conditions being equal. This, in particular, means that the supplement of the nanoparticles into the fluid will be most effective for the base fluid with low thermal conductivity. Nevertheless, the effect of base fluid properties on the effective thermal conductivity of nanofluid is still poorly studied. Here it is necessary to consider many different factors, for example, the formation of the electrical double layer around the nanoparticles (see [49]), the hydrophilicity or hydrophobicity of nanoparticles, etc. Finally, it is necessary to study further the effect of surfactants on the nanofluid thermal conductivity.

The work is carried out at partial financial support of the Russian Scientific Foundation (Agreement No. 14-19-00312).

\section{References}

1. Masuda, H. et al., 1993, Alteration of thermal conductivity and viscosity of liquid by dispersing ultra-fine particles (dispersions of $\gamma-\mathrm{Al}_{2} \mathrm{O}_{3}, \mathrm{SiO}_{2}$, and $\mathrm{TiO}_{2}$ ultra-fine particles). Netsu Bussei Japan, V. 4, pp. 227-239.

2. Wang, X., Xu, X., and Choi, S.U.S., 1999, Thermal conductivity of nanoparticle-fluid mixture. J. Thermophys. Heat Trans., V. 13, No.4, pp. 474-480.

3. Wang, X-Q., Mujumdar, A.S., 2007, Heat transfer characteristics of nanofluids: a review. Int. J. Thermal Sciences, V. 46, pp. 1-19.

4. France, Yu., Routbort, W., and Choi, D.M., 2008, Review and comparison of nanofluid thermal conductivity and heat transfer enhancements. Heat Transfer Eng., V. 29, No.5, pp. 432-460.

5. Kleinstreuer, K., and Yu, F., 2011, Experimental and theoretical studies of nanofluid thermal conductivity enhancement: a review. Nanoscale Research Lett., V. 6, No. 229, pp. 1-13.

6. Chon, C.H., Kihm, K.D., Lee, S.P., and Choi, S.U.S., 2005, Empirical correlation finding the role 
of temperature and particle size for nanofluid $\left(\mathrm{Al}_{2} \mathrm{O}_{3}\right)$ thermal conductivity enhancement. Appl. Phys. Lett., 87:153107.

7. Li, C.H., and Peterson, G.P., 2007, Effect of particle size on the effective thermal conductivity of $\mathrm{Al}_{2} \mathrm{O}_{3}$-water nanofluids. J. Appl. Phys., 101:044312.

8. Mintsa, H.A., Roy, G., Nguyen, C.T., and Doucet, D., 2009, New temperature dependent thermal conductivity data for water-based nanofluids. Int. J. Thermal Sci., V. 48, pp. 363-371.

9. Chopkar, M., Sudarshan, S., Das, P.K., and Manna, I., 2008, Effect of particle size on thermal conductivity of nanofluid. Metal Mater Trans., V. 39, pp. 1535-1542.

10. Hong, J., Kim, S.H., Kim, D., 2007, Effect of laser irradiation on thermal conductivity of ZnO nanofluids. J. Phys., Conference Series, V. 59, pp. 301-304.

11. He, Y., Jin, Y., Chen, H., Ding, Y., Cang, D., and Lu, H., 2007, Heat transfer and flow behavior of aqueous suspensions of $\mathrm{TiO}_{2}$ nanoparticles (nanofluids) flowing upward through a vertical pipe. Int. J. Heat Mass Transfer, V. 50, No.11, pp. 2272-2281.

12. Lee, J.-H., Lee, S.-H., and Jang, S.P., 2014, Do temperature and nanoparticle size affect the thermal conductivity of alumina nanofluids? Applied Physics Letters V. 104, No. 16, pp. 1908.

13. Kim, S.H., Choi, S.R., and Kim, D., 2007, Thermal conductivity of metal-oxide nanofluids: Particle size dependence and effect of laser irradiation. ASME J. Heat Transf. V. 129, pp. 298307.

14. Chen, G., Yu, W., Singh, D., Cookson, D., and Routbort, J., 2008, Application of SAXS to the study of particle size dependent thermal conductivity in silica nanofluids. J. Nanopart. Res. V. 10, pp. 1109-1114.

15. Beck, M.P., Yuan, Y., Warrier, P., and Teja, A.S., 2009, The effect of particle size on the thermal conductivity of alumina nanofluids. J. Nanopart. Res., V. 11, pp. 1129-1136.

16. Timofeeva, E.V., Gavrilov, A.N., McCloskey, J.M. et al., 2007, Thermal conductivity and particle agglomeration in alumina nanofluids: Experiment and theory. Phys. Rev., E 76, 061203.

17. Timofeeva, E.V., Yu, W., France, D.M., Singh, D., Routbort, J.L., 2011, Base fluid and temperature effects on the heat transfer characteristics of $\mathrm{SiC}$ in ethylene glycol/ $/ \mathrm{H}_{2} \mathrm{O}$ and $\mathrm{H}_{2} \mathrm{O}$ nanofluids. J. Appl. Phys. 109:014914.

18. Timofeeva, E.V., Smith, D.S., Yu, W., France, D.M., Singh, D., and Routbort, J.L., 2010, Particle size and interfacial effects on thermo-physical and heat transfer characteristics of water-based $\alpha$ SiC nanofluids. Nanotechnology, 21:215703.

19. Shalkevich, N., Escher, W., Burgi, T., Michel, B., Ahmed, L.S., Poulikakos, D., 2010, On the thermal conductivity of gold nanoparticle colloids. Langmuir, V. 26, pp. 663-670.

20. Wenhua, Y., France, D.M., Jules, L.R., Choi, S.U.S, 2008, Review and comparison of nanofluid thermal conductivity and heat transfer enhancements. Heat Transfer Engineering, V. 29, No. 5, 
pp. 432-460.

21. Maxwell, J. C., 1881, A treatise on electricity and magnetism. Oxford, Clarendon Press.

22. Rashmi, W., Khalid, M., Ong, S.S., Saidur, R., 2014, Preparation, thermo-physical properties and heat transfer enhancement of nanofluids. Materials Research Express. V. 1. p. 032001.

23. Kumar, P.M., Kumar, J., Tamilarasan, R., Sendhilnathan, S., and Suresh, S. 2015, Review on nanofluids theoretical thermal conductivity models. Engineering Journal, V. 19, No. 1, pp. 67-83.

24. Lee, J.-H., Lee, S.-H., Choi, C., Jang, S., Choi, S., 2010, A review of thermal conductivity data, mechanisms and models for nanofluids. International Journal of Micro-Nano Scale Transport, V. 1, No. 4, pp. 269-322.

25. Dmitriev, A.S., Fluctuation hydrodynamics, thermophoresis of nanoparticles and heat transfer in nanofluids Proceedings of the 3th Micro/Nanoscale Heat \& Mass Transfer International Conference. March 3-6, 2012, Atlanta, Georgia, USA. MNHMT 2012-75205.

26. Angayarkanni, S.A., Philip, J. 2015, Review on thermal properties of nanofluids: Recent Developments, Advances in Colloid and Interface Science, V. 225, pp. 146-176.

27. Minakov, A.V., Rudyak, V.Y., Guzei, D.V., Pryazhnikov, M.I., and Lobasov, A.S., 2015, Measurement of the thermal-conductivity coefficient of nanofluids by the hot-wire method. Journal of Engineering Physics and Thermophysics, V. 88, No. 1, pp. 149-162.

28. Bruggeman, D.A.G., 1935, Berechnung verschiedener physikalischer Konstanten von heterogenen Substanzen. I. Dielektrizitatskonstanten undleitfahigkeiten der Mischkorper aus isotropen Substanzen. Annalen der Physik, Bd. 24, 636-679.

29. Hamilton, R.L., and Crosser, O.K., 1962, Thermal conductivity of heterogeneous two-component systems. I\&EC Fundam., V.1, pp.182-191.

30. Zhu, H.T., Zhang, C.Y., Tang, Y.M., and Wang, J.X., 2007, Novel synthesis and thermal conductivity of $\mathrm{CuO}$ nanofluid. J. Phys. Chem. C., V. 111, No. 4, pp. 1646-1650.

31. Keblinski, P., Prasher, R., Eapen, J., 2008, Thermal conductance of nanofluids: is the controversy over? J. Nanopartarticles Res., V. 10, pp. 1089-1097.

32. Rudyak, V.Ya., and Belkin, A.A., 2010, Simulation of transport coefficients. Nanosystems: Physics, Chemistry, Mathematics., V. 1, No. 1, pp. 156-177.

33. Rudyak, V.Y., Belkin, A.A., and Tomilina, E.A., 2010, On the thermal conductivity of nanofluids. Technical Physics Letters, V. 36(14), pp. 49-54.

34. Kang, H.U., Kim, S.H., and Oh, J.M., 2006, Estimation of thermal conductivity of nanofluids using experimental effective particle volume. Experimental Heat Transfer, V.19, No.3, pp. 181191.

35. Manna, I., Chopkar, M., and Das, P.K., 2006, Synthesis and characterization of nanofluid for advanced heat transfer applications. Scripta Materialia. V. 55, pp. 549-552. 
36. Pak, B.C. and Cho, Y.I., 1998, Hydrodynamic and heat transfer study of dispersed fluids with submicron metallic oxide particles, Experimental Heat Transfer an International Journal, V. 11, No. 2, pp. 151-170.

37. Turgut, A., Tavman, I., Chirtoc, M., Schuchmann, H.P., Sauter, C., and Tavman, S., 2009, Thermal conductivity and viscosity measurements of water-based $\mathrm{TiO}_{2}$ nanofluids, Int $\mathrm{J}$ Thermophys, V. 30, pp. 1213-1226.

38. Duangthongsuk, W., Wongwises, S., 2009. Measurement of temperature-dependent thermal conductivity and viscosity of $\mathrm{TiO}_{2}-$ water nanofluids. Exp. Therm. Fluid Sci. 33 (4), 706-714

39. Das, S.K., Putra, P.P., Thiesen, and W. Roetzel, 2003, Temperature dependence of thermal conductivity enhancement for nanofluids, J. Heat Transf., V. 125, pp. 567-574.

40. Eastman, J.A., Choi, U.S., Li, S., Thompson, L.J., and Lee, S., 1997, Enhanced thermal conductivity through the development of nanofluids, Proceedings of the Materials Research Society Symposium, V. 457, Materials Research Society, Pittsburgh, PA, pp. 3-11.

41. Ceotto, D., Rudyak, V.Ya., 2016, Phenomenological formula for the thermal conductivity coefficient of water based nanofluids. Colloid Journal, V. 78, No. 4, pp. 1-6.

42. Tsai, T.-H., Kuo, L.-S., Chen, P.-H., and Yang, C.-T., 2009, Thermal Conductivity of Nanofluid with Magnetic Nanoparticles. PIERS ONLINE, V. 5, No. 3, pp. 231-234.

43. Xuan, Y., Li, Q., Zhang, X., and Fujii, M., 2006, Stochastic thermal transport of nanoparticle suspensions, Journal of Appied Physics, 100, pp. 043507-1 - 043507-6.

44. Beck, M. P., Thermal conductivity of metal oxide nanofluids. The PhD thesis. Georgia Institute of Technology. 14-15 December 2008.

45. Li, Q. and Y.M. Xuan, 2000, Experimental investigation on transport properties of nanofluids. Heat Transfer Science and Technology, p. 757-762.

46. Xie, H., Lee, H., Youn, W., and Choi, M., 2003, Nanofluids containing multiwalled carbon nanotubes and their enhanced thermal conductivities. Journal of Applied Physics, V. 94, No. 8, pp. 4967-4971.

47. Yu, W., France, D.M., Choi, S.U.S., and Routbort, J.L., 2007, Review and assessment of nanofluid technology for transportation and other applications. Energy System Division, Argonne National Laboratory, Argonne, pp. 109-116

48. Timofeeva, E.V., 2011, Nano-fluids for heat transfer-potential and engineering strategies, Two Phase Flow, Phase Change and Numerical Modelling, pp. 1-17.

49. Lee, D., 2007, Thermophysical properties of interfacial layer in nanofluids. Langmuir, 23, pp. 6011-6018. 